\title{
CARDIAC VALVE ENDOTHELIAL CELLS: RELEVANCE IN THE LONG-TERM FUNCTION OF BIOLOGIC VALVE PROSTHESES
}

\author{
A. Simon, DrMed ${ }^{\mathrm{a}}$ \\ M. Wilhelmi ${ }^{\mathrm{a}}$ \\ G. Steinhoff, ProfDrMed ${ }^{\text {b }}$ \\ W. Harringer, DrMed ${ }^{b}$ \\ P. Brücke, ProfDrMed ${ }^{c}$ \\ A. Haverich, ProfDrMed ${ }^{\text {b }}$
}

\begin{abstract}
Objective: For reasons that are still unclear, biologic heart valve prostheses undergo degeneration after implantation. We studied the possible role of the immune system in this process. Methods: We examined the expression of immunologically relevant molecules by human cardiac valve endothelium in situ and in vitro and studied re-endothelialization of implanted allogeneic and xenogeneic valvular surfaces using explanted bioprostheses and valves obtained from donor hearts at cardiac retransplantation. Results: We demonstrate that human cardiac valve endothelial cells express molecules capable of initiating immune responses and might therefore play a role in the degeneration of viable cardiac valve prostheses. Also, we show evidence of re-endothelialization on the surfaces of xenografts and allografts but not on valves obtained from previously transplanted hearts. Conclusion: Inasmuch as valves from previously transplanted hearts seem to be free from degeneration, we conclude that reduction of the immunogenicity of allograft valve prostheses by HLA matching or immunosuppressive treatment might further improve long-term results after allograft valve replacement. ( $J$ Thorac Cardiovasc Surg 1998;116:609-16)
\end{abstract}

\begin{abstract}
Alogeneic heart valves are theoretically ideal for A replacement of any cardiac valve. Advances in the procurement of allograft heart valve prostheses have resulted in better availability and viability, thereby potentially enhancing long-term survival. ${ }^{1}$ However, the use of these prostheses is limited, because biologic heart valve prostheses undergo degeneration after implantation, which leads to their destruction. The factors causing this process are not understood, and growing evidence suggests that, besides mechanical stress, immunogenic properties of the implant (eg, viable endothelial cells) contribute to the long-term deterioration. $\mathrm{We}^{2}$ have previously demonstrated the immunogenic potential of human cardiac valve endothelium (HCVE) in vitro.
\end{abstract}

From the Department of Cardiovascular Surgery, ${ }^{\text {a }}$ University Hospital, "Christian Albrechts Universität zu Kiel," Germany; Department of Cardiothoracic and Vascular Surgery, Medizinische Hochschule Hannover, Germany; and the Department of Surgery, ${ }^{\mathrm{c}}$ General Hospital, Linz, Austria.

Received for publication Aug 19, 1997; revisions requested Oct 1, 1997; revisions received June 5, 1998; accepted for publication June 8, 1998.

Address for reprints: André R. Simon, MD, Klinik für Herz-, Thorax- und Gefässchirurgie, Medizinische Hochschule Hannover, Carl Neuberg Str, 30623 Hannover, Germany.

Copyright $\odot 1998$ by Mosby, Inc.

0022-5223/98 \$5.00+ $0 \quad \mathbf{1 2 / 1 / 9 2 3 0 8}$
In the current study, we have further examined the immunogenicity of HCVE from explanted valves and valve prostheses using antibodies against endothelial adhesion molecules. We found that HCVE can express molecules such as intercellular adhesion molecule-1 (ICAM-1, CD54) or E-selectin (CD62E), which play critical roles in peripheral blood mononuclear cell attachment to and arrest on the vascular wall, ${ }^{3,4}$ an important step in the initiation of immune responses. For instance, using a mouse cardiac transplantation model, Isobe and associates ${ }^{5}$ demonstrated that inhibition of CD54 receptor interaction with its ligand, leukocyte function-associated antigen (LFA-1), completely prevents rejection of the implant and leads to long-term graft acceptance.

Stimulation of endothelium can lead to its increased immunogenicity (eg, major histocompatibility complex [MHC] class II up-regulation) and stimulation of immune responses in vitro. On cardiac valve prostheses, this might lead to the removal of the endothelial lining, subsequently rendering the implant more susceptible to mechanical stress. To further address the role of HCVE in the degeneration of biologic heart valve implants, we analyzed the surface and the internal structure of such valvular substitutes using immunohistochemistry on cryostat sections of valves and valve prostheses obtained during replacement operation, rereplacement or cardiac transplantation, and retransplanta- 
tion. We showed that HCVE expresses adhesion molecules such as platelet endothelial cell adhesion molecule (CD31) and human cellular adhesion molecule (CD44), known to be involved in homing, adhesion, and migration of immunocompetent cells to tissues as well as costimulation of $\mathrm{T}$ cells via the T-cell reactivity/costimulatory molecule pathway. ${ }^{6,7}$ To differentiate between donor and recipient origin of cells, we used monoclonal antibodies specific for donor and recipient MHC class I molecules. We could show a partial reendothelialization process on xenoprosthetic and alloprosthetic valves of recipient origin after long-term clinical implantation. In contrast, on surfaces of valves obtained from previously transplanted hearts, a confluent layer containing HCVE could be detected showing no signs of re-endothelialization by the recipient. This observation is striking, because these valves appear to be resistant to degeneration, being implanted when fully viable, without previous cryopreservation, into a recipient receiving systemic immunosuppression. These findings suggest an important role of the immune system in the long-term function of allograft valve prostheses and lead us to the hypothesis that implantation of a fully viable allograft prosthesis, matched to the HLA phenotype of the recipient, might be a way to further improve long-term results after allograft valve implantation.

\section{Materials and methods}

Cell cultures. Valves used for harvesting of endothelial cells were obtained from patients undergoing elective aortic valve replacement for valvular insufficiency. HCVE was obtained by means of a technique previously described ${ }^{2}$ and cultured in chamber slide culture chambers, 6- and 96-well microtiter plates (Nunc A/S, Roskilde, Denmark) at $37^{\circ} \mathrm{C}$ and $5 \%$ carbon dioxide until confluence. Cell cultures were fed by exchange of medium when necessary. For all experiments, primary cultures were used as soon as a confluent monolayer had developed.

Explanted valves. Reference aortic valves $(n=6)$ were obtained at the time of replacement for valvular insufficiency (4/6) and from donor hearts rejected for transplantation (2/6). Explanted allograft prostheses were obtained at the time of reoperation for insufficiency and stenosis $(\mathrm{n}=12$, duration of implantation 3-12 years, 4 pulmonary frozen homografts [group A]; 6 aortic frozen homografts [group B], 2 undetermined [group C]). Explanted xenograft prostheses $(n=6,5$ glutaraldehyde-treated stented porcine xenografts, 1 glutaraldehyde-treated stented bovine xenograft) were obtained at the time of second replacement for insufficiency (duration of implantation 4-12 years). Valves from previously transplanted hearts were obtained at the time of retransplantation or valve replacement $(n=4$, duration of implantation 1-4 years). Thus obtained specimens were snap-frozen in liquid nitrogen, cut into $5 \mu \mathrm{m}$ sections, and used for immunohistochemical staining.
Aortic endothelium and endocardium. Aortic endothelium and endocardium were obtained at the time of transplantation and cardiectomy for transplantation, both from donors and recipients or from hearts used for heart valve banking. Additional endothelial cells were obtained at routine endomyocardial biopsies after cardiac transplantation. The material was immediately snap-frozen and stored in liquid nitrogen until further use. Tissue was cut in $5 \mu \mathrm{m}$ sections and stained with the use of the panel of antibodies described herein.

HLA phenotypes. Four allograft recipients (2 group A, 2 group B) and all patients undergoing retransplantation underwent HLA typing to differentiate between potential donor and recipient cells on the surface of the prostheses. Complete HLA data were available for 1 valve donor.

Valve donor:

VD1: HLA-A2 B7,40 BW3,6 Cw3,7 DR2,4(53) DQ3,7

Valve recipients:

VR1:HLA-A1,3 B8,7 Cw7 DR2(15),5(11) DQ1,3(7)

VR2: HLA-A2,9(23) B21(50),12(44) Cw5,6 DR1,7 DQ1(5),2

VR3: HLA-A2,3 B7 (no DR available)

VR4(VD1): HLA-A1,2 B13,7 Cw6 DR6,7

Patients undergoing retransplantation:

rTX1: HLA-A2,26 B60 CW3 DR1,12

rTX2: HLA-A2,30 B39,51 DR1,4

rTX3: HLA-A2,26 B51,60 DR1,6

rTX4: HLA-A2,11 B37,52 Cw2 DR2,1

Donors of original (first) hearts of patients undergoing retransplantation:

D1(rTX2): HLA-A2 B27,35 Cw2,4 DR1,11

D2(rTX4): HLA-A1,10(26) B8,12 DR,6

Antibodies. All primary antibodies were monoclonal (mAb). W6/32 (anti-class I heavy chain) was obtained from American Type Culture Collection (ATCC, Manassas, Va). Anti-CD29, CD31, CD34, CD44, CD49a, CD49c, CD49d, CD49e, CD49f, CD51, CD54, CD62P, CD106, anti-H/Y $\mathrm{mAb}$ and anti-factor VIII-related antigen monoclonal antibodies (anti-FVIII-related Ag mAb) were purchased from Immunotech (Hamburg, Germany). Additional anti-FVIIIrelated $\mathrm{Ag} \mathrm{mAb}$ were purchased from DAKO (Dakopats, Hamburg, Germany). Anti-CD49b mAb were from Becton Dickinson (Heidelberg, Germany). Anti-CD62E mAb were from Dianova (Hamburg, Germany). Anti-CD102 mAb were from Bender \& Co GmbH (Vienna, Austria). Alkaline phosphatase anti-alkaline phosphatase (APAAP) and immune peroxidase (POD) secondary $\mathrm{mAb}$ were from DAKO. Enzyme coupled anti-secondary APAAP mAb were from Dianova. Primary antibodies used and the primary function of their corresponding antigens are summarized in Table IA. Anti-HLA antibodies (see Table IB), which were used to differentiate between donor and recipient cells, were kindly provided by Dr Westphal (Institute of Immunology, Christian Albrechts Universität Kiel, Kiel, Germany).

Immunohistochemical staining of cells and cryostat sections. Cells/cryostat sections were fixed in acetone at $-20^{\circ} \mathrm{C}$ for 10 minutes. Slides were washed 3 times for 2 minutes in tris-buffered saline solution. The sections and cells adhering 
Table IA. Antibodies used

\begin{tabular}{lcl}
\hline Antigen & Family & Primary antigen function \\
\hline MHC class I heavy chain & HLA (A, B, C) & Self/non-self recognition \\
MHC class II & HLA (DR) & Restriction of immune response \\
FVIII-related Ag/vWF & & Activation of endogenous coagulation \\
H/Y & & Blood group antigen \\
CD29/VLA $\beta_{1}$-chain & Integrins & $\beta_{1}$ Integrin subunit; forms heterodimer with VLA $\alpha$-chains, T-cell activation \\
CD31/PECAM-1 & IG supergene & Initiation of leukocyte/thrombocyte EC adhesion \\
CD34 & Complementary CAMs & Selectin ligand \\
CD44/ECM R III & & Cell homing receptor \\
CD49a/VLA-1 $\alpha$-chain & Integrins & $\alpha_{1}$ Integrin chain, attachment to and migration through ECM \\
CD49b/VLA-2 $\alpha$-chain & Integrins & $\alpha_{2}$ Integrin chain, see CD49a \\
CD49c/VLA-3 $\alpha$-chain & Integrins & $\alpha_{3}$ Integrin chain, see CD49a \\
CD49d/VLA-4 $\alpha$-chain & Integrins & $\alpha_{4}$ Integrin chain, see CD49a, VCAM-1 (CD106) receptor \\
CD49e/VLA-5 $\alpha$-chain & Integrins & $\alpha_{5}$ Integrin chain, see CD49a \\
CD49f/VLA-6 $\alpha$-chain & Integrins & $\alpha_{6}$ Integrin chain, see CD49a \\
CD51/VNR $\alpha$-chain & Integrins & Cell-matrix adhesion \\
CD54/ICAM-1 & IG supergene & Ligand for LFA-1 and Mac-1, leukocyte adhesion \\
CD62E/ELAM-1 & Selectins & Initiation of leukocyte-EC adhesion \\
CD62P/PADGEM & Selectins & Initiation of leukocyte-EC adhesion \\
CD102/ICAM-2 & IG supergene & Lymphocyte-EC adhesion \\
CD106/VCAM-1 & IG supergene & Leukocyte-EC adhesion \\
\hline
\end{tabular}

FVIII-related $A g / v W F$, Factor VIII-related antigen/von Willebrand factor; VLA, very late activation; PECAM-1, platelet endothelial cell adhesion molecule-1; IG, immunoglobulin; $C A M s$, cell adhesion molecules; ECM R, extracellular matrix receptor; VCAM-1, vascular cell adhesion molecule-1; VNR, vitronectin receptor; $L F A$, leukocyte function-associated antigen; $E C$, endothelial cell; PADGEM, $\alpha$-granule membrane protein-140 (P-selectin).

to the bottom of the culture chambers or wells were incubated with the primary antibodies for 30 minutes at $37^{\circ} \mathrm{C}$ in a humidified atmosphere and stained by means of an APAAP method or a POD method previously described. ${ }^{2}$

\section{Results}

\section{Characterization of HCVE}

HCVE in vitro. Cell morphology was normal for HCVE, with cells growing to confluent monolayers within the first 4 to 7 days (Fig 1). A detailed description of HCVE morphology has been published before. ${ }^{2}$ In brief, cells were shaped irregularly, showed contact inhibition, and grew in monolayers without detectable growth patterns. In all cell cultures, characteristic stigmata could be observed. Fibroblast contamination could be detected easily by their typical spindle-shaped appearance, their whorl-like growth, and lack of contact inhibition.

HCVE on valve surfaces. Valves obtained at initial replacement and from recipient hearts at the time of transplantation or from beating heart donor organs rejected for transplantation had intact endothelial lining (Fig 2, A). Cells grew as a confluent monolayer on the basal membrane. Valves from explanted first donor hearts obtained at the time of retransplantation showed largely or completely intact endothelial lining also, giving them the same overall appearance as normal valves. Explanted allograft or xenograft valves showed completely or largely denuded surfaces. Only tiny areas could be shown to bear endothelial cells directly adher-
Table IB. Monoclonal antibodies to polymorphic MHC class I epitopes used for donor/recipient differentiation

\begin{tabular}{lc}
\hline Antibody & Clone/name $^{31}$ \\
\hline Anti-HLA-A1 & $108 \mathrm{~A} 6$ \\
Anti-HLA-A2 & $48 \mathrm{C} 1$ \\
Anti-HLA-A10 & $66 \mathrm{C} 4$ \\
Anti-HLA-B7 & $38 \mathrm{D} 4$ \\
Anti-HLA-BW6 & 2BC4
\end{tabular}

MHC, Major histocompatibility complex; $H L A$, human leukocyte antigen.

ent to the valve surface. Also, thrombotic material could be found on the exterior of the prostheses (Fig. 2, B).

Internal structure. A description of the "normal" morphology of cryostat sections of heart valves has been given by us and others before. ${ }^{8,9}$ Basically, valves obtained at initial replacement or retransplantation appeared as normal valves with intact endothelial lining and interior fibroelastic structure in which stromal cells could be demonstrated (Fig 2, A, and 4). Allogeneic or xenogeneic valves replaced at rereplacement showed breakup of internal collagenous structure (Fig 2, B, and 3). The interior of the prostheses showed areas of calcification and infiltrating cells. No stromal cells of donor origin could be shown.

\section{Expression of cell surface molecules of $\mathrm{HCVE}$}

Reference aortic valves. On microscopic examination, a continuous monolayer could be detected on the surfaces of valves obtained at a primary aortic valve 


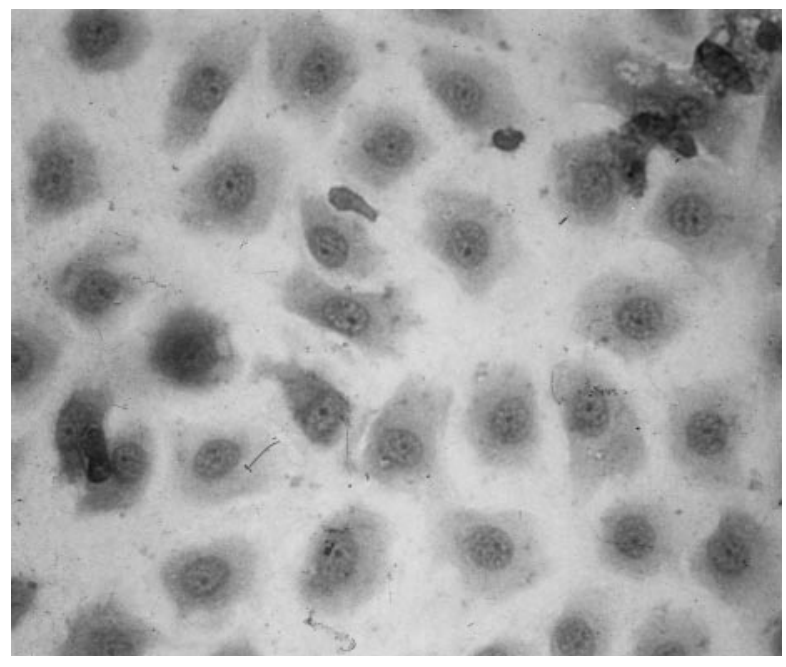

Fig 1. HCVE in vitro (APAAP stain, original magnification $\times 700$ ). Confluent monolayer of valvular endothelium in in vitro culture. Cells are stained for MHC class I antigens. Typical appearance, showing that cells are polygonal and grow as confluent monolayer without detectable growth pattern. Cell borders are not identifiable. Nuclei are central with 1 to 3 nucleoli.

replacement. Immunohistochemical analyses demonstrated that these cells were positive for the W6/32 (MHC class I), anti-H/Y, CD31, CD34, CD44, CD49a, CD49c, CD49e, CD49f, CD51, and CD54 antibodies (Fig 1). This layer stained negatively for FVIII-related $\mathrm{Ag}$, as we previously reported, and negative for CD49b, CD49d, CD62E, CD62P, CD102, and CD106 (Table II).

Explanted allograft valves. On 3 allograft valve surfaces, cells could be detected that were positive for the basic antibody panel described earlier as characteristic of HCVE. They were also positive for FVIII-related Ag and CD62P (Table II, Fig 3).

Valves from transplanted hearts. On valves from transplanted hearts, the observed monolayer was not always continuous. The endothelial cells showed a similar phenotype (Fig 4), although some differences were observed (Table II). These layers partially stained positive for FVIII-related Ag also. In addition, cells could be detected on the surface of those valves that were negative for $\mathrm{H} / \mathrm{Y}$, surprisingly. In contrast to the cell population described earlier, these cells were positive for CD49b but negative for CD49f, CD51, and CD54 (Table II).

Explanted xenograft valves. On 2 xenograft valves, a discontinuous cell lining could be detected directly adherent to the valve, staining positive for the panel characteristic for HCVE (Table II) after stimulation with cytokines. These results confirm previously mentioned observations. ${ }^{10}$ The xenograft valve taken from a
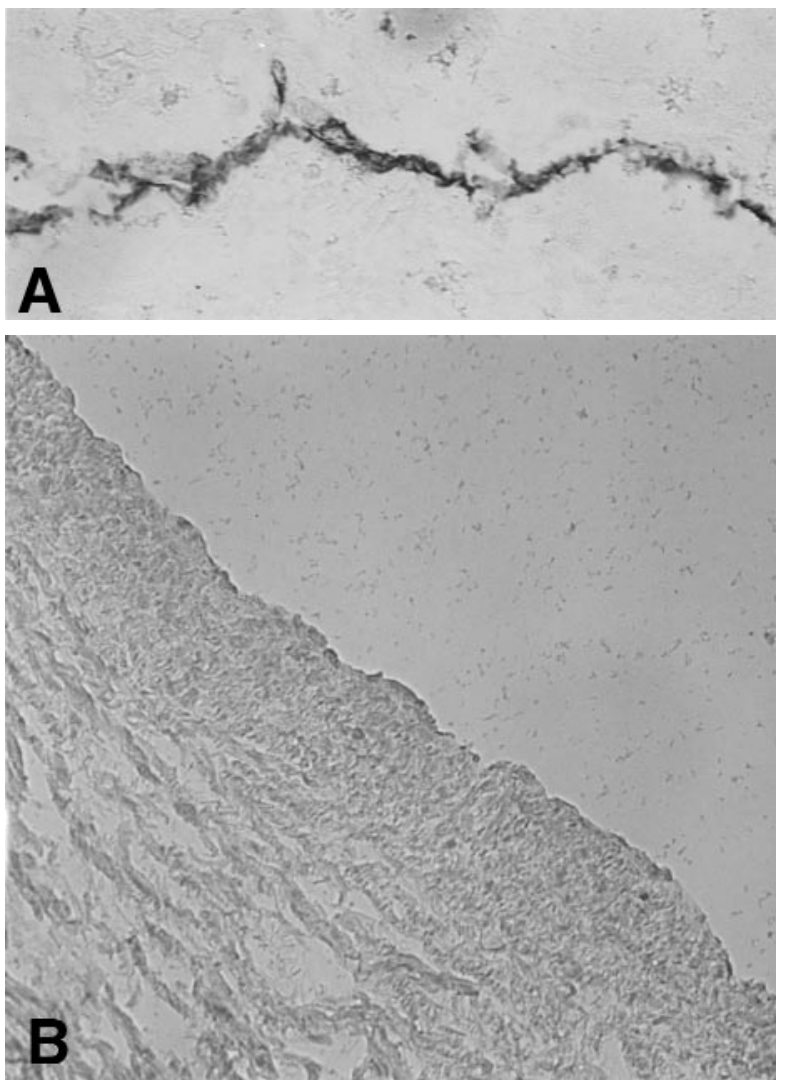

Fig 2. Cryostat sections. A, Reference aortic valve (APAAP stain, original magnification $\times 400)$. Typical appearance of endothelial layer on "normal valves" and valves from previously transplanted hearts. Valve is stained for expression of CD31 antigens, showing complete endothelial lining. Expression of CD31 is restricted to the endothelial cells. Internal tissue was well preserved, showing no signs of calcification or degeneration. B, Explanted allograft valve prosthesis (POD stain, original magnification $\times 200$ ). Typical appearance of explanted allograft valve, showing denuded surface and breakup of internal structure.

heart at the time of retransplantation was negative for all antibodies on its surface. It showed a completely denuded surface. No cell lining could be detected.

Donor-recipient differentiation of cells on valve surfaces

Explanted allograft valves. With the use of antibodies specific for donor and recipient HLA types, cells of definite recipient origin could be detected on the surface of 1 of the allograft valves studied. On 2 additional valves, cells could be detected staining only positive for the recipient panel, while being negative for nonrecipient phenotypes. Therefore it is extremely likely that these cells are of recipient origin.

Valves from transplanted hearts. When donor- and 
Volume 116, Number 4

Table II. Synopsis of immunohistochemical staining of aortic heart valves

\begin{tabular}{|c|c|c|c|c|c|c|}
\hline Antibody & Normal AE & Normal EC & $\begin{array}{c}\text { Normal } \\
\text { aortic valve } \\
\text { endothelium }\end{array}$ & $\begin{array}{c}\text { Explanted } \\
\text { allograft } \\
\text { valve }\end{array}$ & $\begin{array}{c}\text { Explanted } \\
\text { xenograft } \\
\text { valve }\end{array}$ & $\begin{array}{c}\text { Valve from } \\
\text { transplanted heart } \\
\text { at re-TX }\end{array}$ \\
\hline MHC class I & ++ & ++ & ++ & ++ & ++ & ++ \\
\hline MHC class II & ND & ND & + & + & + & + \\
\hline FVIII-related Ag & - & - & - & ++ & + & $+/-$ \\
\hline $\mathrm{H} / \mathrm{Y}$ & - & $?$ & ++ & ++ & ++ & $++/-$ \\
\hline $\mathrm{CD} 29$ & ND & ND & + & + & ND & + \\
\hline CD31 & ++ & + & ++ & ++ & ++ & ++ \\
\hline CD34 & ++ & ++ & + & ND & ND & - \\
\hline CD44 & ++ & ++ & ++ & ND & ND & ++ \\
\hline CD49a & ++ & ++ & ++ & ND & ND & ++ \\
\hline $\mathrm{CD} 49 \mathrm{~b}$ & - & - & - & - & ND & $+/-$ \\
\hline $\mathrm{CD} 49 \mathrm{c}$ & ++ & ++ & ++ & ND & ND & + \\
\hline CD49d & - & - & - & - & ND & - \\
\hline CD49e & + & - & ++ & + & ND & - \\
\hline CD49f & + & $+/-$ & ++ & - & ND & $+/-$ \\
\hline CD51 & + & - & ++ & ND & ND & $+/-$ \\
\hline CD54 & ++ & ++ & ++ & + & + & $+/-$ \\
\hline CD62E* & - & - & - & - & - & + \\
\hline CD62P & - & - & - & + & - & - \\
\hline CD102 & - & $-/+$ & - & - & - & - \\
\hline CD106 & + & - & - & + & - & - \\
\hline
\end{tabular}

$A E$, Aortic endothelium; $E C$, endothelial cells; Re-TX, Retransplantation; $M H C$, major histocompatibility complex; FVIII-related Ag, factor VIII-related antigen; ND, not determined; -, negative; +/-, singular cells, weakly positive; +, positive; ++, strongly positive. Boldface: On the surface of valves from hearts of the first donor, obtained at the time of retransplantation, cell populations with differences in their expression of surface molecules could be shown.

*CD62E (ELAM-1, endothelial cell leukocyte adhesion molecule) expression has been shown to be inducible.

recipient-specific antibodies were used to differentiate cells on the surface of valves from transplanted hearts, no cells could be detected on the valve surface that were of definite recipient origin. However, infiltration of cells clearly shown to be of recipient origin could be demonstrated in the interior of the valves.

Explanted xenograft valves. Because all cells found on xenograft surfaces must be of recipient origin, no differentiation was attempted. We could show viable cells resembling human umbilical vein endothelial cells on the surface of 2 explants.

Expression of cell surface molecules of aortic endothelium and endocardium. Aortic endothelium and endocardium were stained by means of the protocol mentioned above. Aortic endothelial cells were positive for the MHC class I, anti-CD31, CD34, CD44, CD49a, CD49c, CD49e, CD49f, CD51, and CD54, which is the same panel of antibodies as HCVE. However, differences in intensity could be detected. In contrast to HCVE, aortic endothelium stained negative for H/Y (Table II). Endothelial cells stained similarly to aortic endothelial cells but were negative for CD49e, CD49f, and CD51 (Table II).

HCVE in vitro. Control stains of HCVE in vitro expressed a panel of molecules identical to that of reference aortic valve endothelium.

\section{Discussion}

The morphology of HCVE in vitro and in vivo has been described by us and others before. We have previously shown that HCVE constitutively expresses not only HLA class I but also class II molecules in vitro and that MHC-molecule expression on HCVE was markedly increased after stimulation with interferon- $\gamma .^{2}$ Also, we reported on the immunogenic properties of HCVE tested in a mixed lymphocyte endothelial cell culture. ${ }^{2}$

In the current study, we analyzed the expression of cell surface molecules known to be involved in rejection and inflammatory responses. Yacoub ${ }^{11}$ could not show MHC class II molecule expression in situ: we demonstrate such expression not only on the surface of valves from transplanted hearts, but also on endothelialized portions of explanted prostheses and valves. The differing expression of class II molecules may be due to different sensitivities of the mAb used or different processing of the valves, but taken together with the previously described expression in vitro and the increase after cytokine stimulation, this suggests that viable HCVE can have an immunostimulatory and sensitizing effect in recipients after allogeneic valve replacement.

An initial step in leukocyte-endothelial attachment is the "rolling" of leukocytes via selectins. ${ }^{4}$ On valvular 

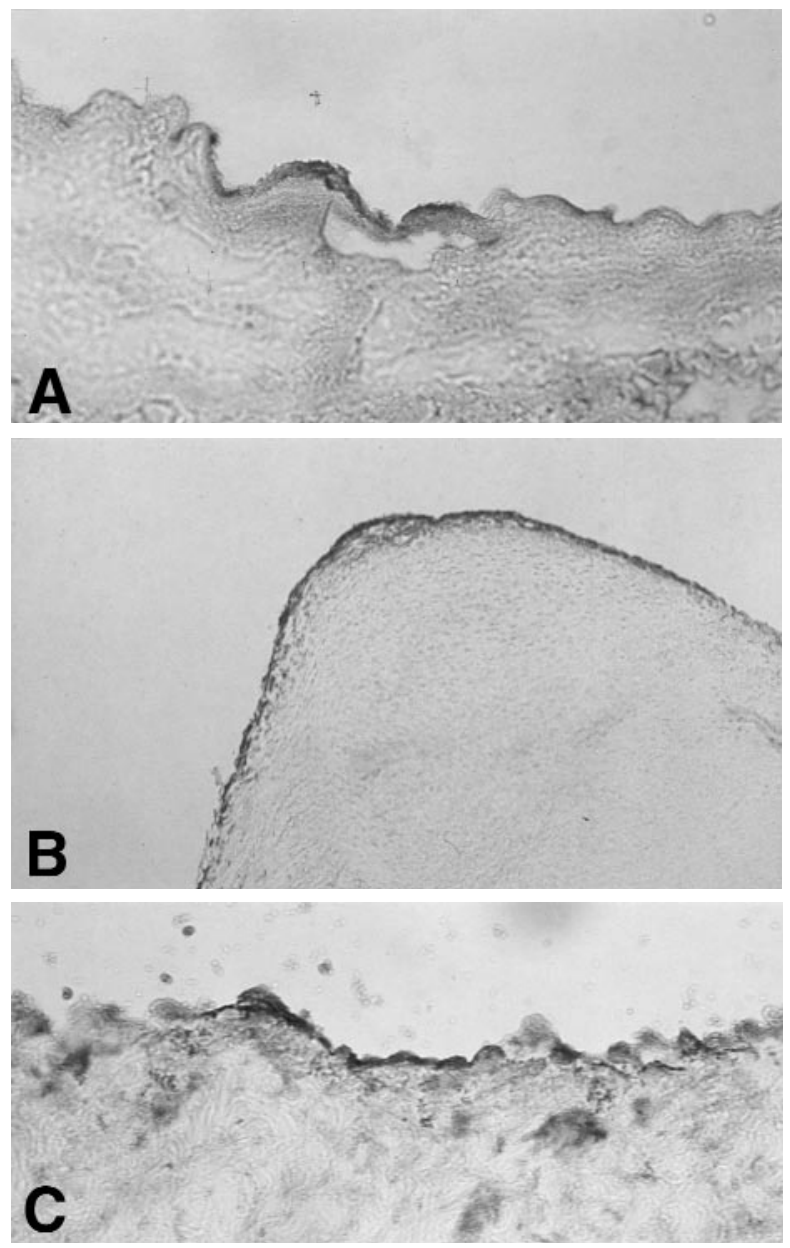

Fig 3. Cryostat sections. Immunohistochemical analysis of sections of explanted aortic valve allograft. A, Leaflet section stained for CD54 antigens, showing partial re-endothelialization. A positive monolayer of cells can be detected on the valvular surface. In other areas of the valve, infiltrating CD54positive cells could be demonstrated (not shown). The internal structure is partially preserved, although breakup and calcification could be demonstrated. (APAAP stain, original magnification $\times 400$.) B, Leaflet section stained for CD62P antigens, showing partial re-endothelialization. A monolayer of cells on the valvular surface can be detected. Staining is contained to the valvular surface. (APAAP stain, original magnification $\times 100$.) C, Leaflet section stained for CD54 antigens, again showing partial re-endothelialization. As with CD62P, the staining is contained to the monolayer of cells on the valvular

surfaces from normal valves and nonstimulated cells in vitro, no expression of E-selectin was observed, although it has been shown to be inducible in vitro. ${ }^{2} \mathrm{In}$ rejection or inflammation, leading to $\mathrm{CD} 62 \mathrm{E}$ induction on HCVE, lymphocytes could therefore attach to the valvular cusps via these fast-acting interactions. Once

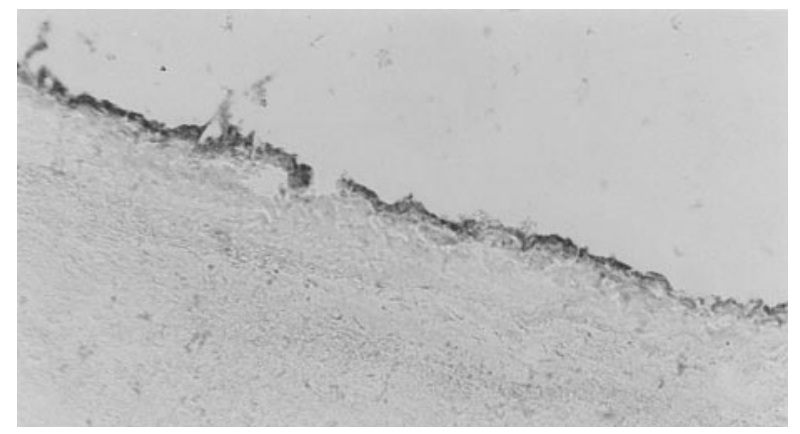

Fig 4. Cryostat section (APAAP stain, original magnification $\times 400$ ). Immunohistochemical staining (anti-CD31) of valve obtained at time of retransplantation, showing a continuous monolayer of positive cells on the surface. The internal structure is well preserved.

host immune cells attach to the endothelial surface, they become firmly adherent via other adhesive interactions (eg, integrins). ${ }^{12,13}$ The specificity of this arrest is assured by expression of homing molecules such as CD44, CD31, and CD34, ${ }^{7,14,15}$ which are able to regulate the avidity of the leukocyte surface receptors by "outside-in" signaling. If arrest occurs, the cells can attack the endothelium, transmigrate through the endothelial lining, or detach themselves. We have demonstrated that HCVE expresses homing receptors such as CD31, CD34, and CD44 and molecules mediating firm adhesion such as CD106, CD102, and CD54 in situ, which enable host leukocytes to attach to the endothelial lining of a valve prosthesis. In addition, certain adhesion molecules have been implicated in providing costimulatory signals. ${ }^{16-18}$ The observed expression of stimulatory molecules and adhesion/ costimulatory receptors on HCVE makes the involvement of immunologic processes in the destruction of valve implants even more probable.

One of the known functions of an endothelial layer is to sustain the collagenous structures beneath it. ${ }^{19}$ The above findings corroborate the hypothesis that deterioration of internal valve structures may be a consequence of de-endothelialization, rendering the valve susceptible to mechanical stress. Johnson and Fass ${ }^{20}$ have shown a relative deficiency of fibronectin synthesis by porcine cardiac valvular endothelium in vitro. If such a deficiency is also to be found in HCVE in vivo, it could have a significant impact on the reparative capacity of HCVE on valvular surfaces, leading to a vicious circle of endothelial and subsequent extracellular matrix destruction on a valve whose endothelial lining has been partially destroyed because of its immunogenic properties. 
Although dendritic cells are thought to play critical roles in the stimulation of alloimmune responses, its has been well established that endothelial cells are central to the stimulation of an alloimmune response too. ${ }^{21-24}$ It is not surprising that the immunologic reaction to a partially viable allograft valve is much weaker than the allogeneic response to a fully viable organ transplant, which is rejected rapidly and completely destroyed. However, valves in transplanted hearts showed almost complete endothelial linings, whereas cryopreserved allograft valves were almost always completely denuded. In addition, while the internal structure of an allograft valve prosthesis seemed largely disrupted, valves obtained from cardiac transplants had intact internal structures. An important factor in the lack of degeneration of valves in cardiac transplants may be the immunosuppression of the recipient, which may lead to better conservation of HCVE and reduced cell loss on the valve surface, thus preserving natural repair mechanisms in the valve.

Interestingly, we could detect cells of different phenotypes (as established by immunohistochemistry) on the surface of the valves from transplanted hearts. One appeared to be quite similar to stimulated HCVE on the basis of H/Y and FVIII-related Ag molecule expression, although the integrin expression differed. The other expressed a panel of cell surface molecules that was different from both the first cell type and normal HCVE. Whereas HCVE expressed an almost identical panel of surface molecules to aortic endothelium, the panel expressed by the cell populations found on the valves from transplanted hearts was closer to that of endocardial cells. Whether this means that the endocardium or any other cell group, such as the valve endothelium itself, is able to repopulate the valve surface of a transplanted heart, however, remains purely speculative. An alternative explanation is that the differences in surface molecule expression are simply the result of different stages of cell activation and stimulation.

The endothelial marker FVIII-related $\mathrm{Ag}$ (von Willebrand factor), a coagulation factor, seems not to be expressed by HCVE on normal valves or in a nonstimulated stage in vitro. Once cells are stimulated by interferon- $\gamma$ in vitro or an inflammatory or rejection processes in vivo, they do express FVIII-related Ag on their surface. ${ }^{2}$ Also, denuded acellular surface areas of valves stained positive for FVIII-related Ag. These findings suggest that inflammation, rejection, or loss of the endothelial lining may increase the thrombogenicity of the valve surface. Our results are supported by repeated reports of thrombotic material adherent to the surface of valves after endocarditis or on biologic valve prostheses after various durations of implantation in recipients.
Xenograft valves had internal structures that were comparable with those of explanted allograft valves. It is unclear how intense and significant the immunologic reaction of xenograft valve recipients to their prosthesis is over the years. However, it is very probable that mechanical stress plays a major role in the degeneration process of this type of biologic heart valve prosthesis. Of course, this also suggests that the long-term degeneration of quickly denuded allograft valves might be due to a large extent to an increase in sensitivity to mechanical stress after their immunologic de-endothelialization. In contrast to studies previously published by other groups, we were able to show a partial reendothelialization of xenograft and allograft valve graft surfaces in vivo. In an earlier study we ${ }^{10}$ reported on the presence of HCVE on surfaces of explanted xenograft valves. The results of the present study corroborate these findings. We could show small HCVEbearing areas on the surface of 3 allograft valves. To our knowledge, we are the first group reporting such reendothelialization. Of course, the functional value of these patches is questionable. On valves of transplanted hearts, no endothelial cells of recipient origin were detected. Also, the internal structures of the valves seemed to be largely intact. However, cells of recipient origin could be detected in the interior of these valves, as has been reported by us and others. ${ }^{8,25}$

The results reported in this study suggest that HCVE may play an important role in the long-term function of allograft valve prostheses and that stimulation of a reendothelialization process in vivo or in vitro might be possible. This may limit degeneration due to mechanical stress. Our findings suggest that factors leading to the destruction of valve allografts may include the endothelium, which triggers immune response mechanisms in the recipient. This might lead to the loss of the endothelial lining and a subsequent structural deterioration of the valve matrix resulting from loss of nutrients and increased susceptibility to mechanical stress. Finally, the stimulation of HCVE and de-endothelialization may increase the valve's thrombogenicity, which could also trigger inflammatory processes and further destroy the prosthetic implant. In this situation, the implant must finally succumb to the combination of ongoing mechanical stress and immunologic reaction.

It seems that the implantation of a biologic heart valve prosthesis, be it a xenogeneic or even a viable allogeneic one, in essence still results in an early loss of viability because of uncontrolled immunologic reactions. It is therefore not surprising that the long-term results after xenograft or allograft valve implantation are reported to reach comparable plateaus while the immunologically protected, fully viable aortic valve in 
a cardiac transplant seems to be almost completely resistant to this degeneration. ${ }^{26}$ Therefore, since immunosuppression of valve recipients is not an alternative but storage of allograft valves in liquid nitrogen is possible for any amount of time, HLA-matching of prospective recipients to their valve could be a feasible approach toward a solution to this problem. This may lead to an increase in the long-term survival of allograft valves after implantation. This hypothesis is corroborated by the observed superior long-term results in HLA-matched over mismatched organs (eg, cardiac transplantations). ${ }^{27-29}$ In xenografts, reseeding of autologous endothelial cells to prevent structural degeneration and decrease thrombogenicity may be used to achieve a similar effect and has already been attempted in vascular prostheses. ${ }^{30}$

We thank Drs D. K. C. Cooper and A. N. Warrens for their careful review of the manuscript.

\section{REFERENCES}

1. O'Brien MF, McGiffin DC, Stafford EG, et al. Allograft aortic valve replacement: long-term comparative clinical analysis of the viable cryopreserved and antibiotic $4^{\circ} \mathrm{C}$ stored valves. J Card Surg 1991;6:534-43.

2. Simon A, Zavazava N, Sievers HH, Müller-Ruchholtz W. In vitro cultivation and immunogenicity of human cardiac valve endothelium. J Card Surg 1993;8:656-65.

3. Springer TA. Adhesion receptors of the immune system. Nature 1990;346:345-434.

4. Kansas GS. Selectins and their ligands: current concepts and controversies. Blood 1996;88:3259-87.

5. Isobe M, Yagita H, Okumura K, Ihara A. Specific acceptance of cardiac allograft after treatment with antibodies to ICAM-1 and LFA-1. Science 1992;255:1125-7.

6. Newman PJ. The biology of PECAM-1. J Clin Invest 1997;99:3-8.

7. Lesley J, Hyman R, Kincade PW. CD44 and its interaction with extracellular matrix. Adv Immunol 1993;54:271-335.

8. Simon AR. Immunologische Bedeutung von humanem Herzklappenendothelium fuer die langfristige Funktion von biologischen Ersatzklappen [abstract]. Ersatzklappen, Thesis, Christian-Albrechts Universität, Kiel, Germany. 1996.

9. Mitchell RN, Jonas RA, Schoen FJ. Structure-function correlations in cryopreserved allograft cardiac valves. Ann Thorac Surg 1995;60:S108-13.

10. Zavazava N, Simon A, Sievers HH, Bernhard A, Müller-Ruchholtz W. Porcine valves are reendothelialized by human recipient endothelium in vivo. J Thorac Cardiovasc Surg 1995;109:702-6.

11. Yacoub MH. Applications and limitations of histocompatibility in clinical cardiac valve allograft surgery. In: Yankah AC, Hetzer R, Ross DN, Somerville J, Yacoub MH, editors. Cardiac valve allografts 1962-1987. 1st ed. Darmstadt/New York: Steinkopff Verlag Darmstadt/Springer Verlag New York; 1987. p. 95-102.

12. Meerschaert J, Furie MB. The adhesion molecules used by monocytes for migration across endothelium include CD11a/CD18, CD11b/CD18, and VLA-4 on monocytes and ICAM-1, VCAM-1, and other ligands on endothelium. J Immunol 1995;154:4099-112.

13. Nakajima H, Sano H, Nishimura T, Yoshida S, Iwamoto I. Role of vascular cell adhesion molecule 1/very late activation antigen 4 and intercellular adhesion molecule 1/lymphocyte function-associated antigen 1 interactions in antigen-induced eosinophil and $\mathrm{T}$ cell recruitment into the tissue. J Exp Med 1994;179:1145-54.

14. Piali L, Albelda SM, Baldwin HS, Hammel P, Gisler RH, Imhof BA. Murine platelet endothelial cell adhesion molecule (PECAM-1)/CD31 modulates beta 2 integrins on lymphokineactivated killer cells. Eur J Immunol 1993;23:2464-71.

15. Healy L, May G, Gale K, Grosveld F, Greaves M, Enver T. The stem cell antigen CD34 functions as a regulator of hemopoietic cell adhesion. Proc Natl Acad Sci U S A 1995;92:12240-4.

16. Murray AG, Khodadoust MM, Pober JS, Bothwell ALM. Porcine aortic endothelial cells activate human T cells: direct presentation of MHC antigens and costimulation by ligands for human CD2 and CD28. Immunity 1994;1:57-63.

17. Shinde S, Wu Y, Guo Y, et al. CD40L is important for induction of, but not response to, costimulatory activity. ICAM-1 as the second costimulatory molecule rapidly up-regulated by CD40L. J Immunol 1996;157:2764-8.

18. Damle NK, Klussman K, Linsley PS, Aruffo A. Differential costimulatory effects of adhesion molecules B7, ICAM-1, LFA-3, and VCAM-1 on resting and antigen-primed CD4+ T lymphocytes. J Immunol 1992;148:1985-92.

19. Freudenberg N, Riese KH, Freudenberg MA. Well established functions of endothelium. Stuttgart/New York: Gustav-FisherVerlag; 1983. p.16.

20. Johnson CM, Fass N. Porcine cardiac valvular endothelial cells in culture. Lab Invest 1983;49:589-98.

21. Brindle NP. Role of vascular endothelial cells in the allograft response. Eye 1995;9(Pt 2):167-72.

22. Gorski A. The role of cell adhesion molecules in immunopathology. Immunol Today 1994;15:251-5.

23. Pober JS, Collins T, Gimbrone MA Jr, Libby P, Reiss CS. Inducible expression of class II major histocompatibility complex antigens and the immunogenicity of vascular endothelium. Transplantation 1986;41:141-6.

24. Pober JS, Doukas J, Hughes CC, Savage CO, Munro JM, Cotran RS. The potential roles of vascular endothelium in immune reactions. Hum Immunol 1990;28:258-62.

25. Melo JQ, Monteiro C, Neves J, et al. The allograft valve in heart transplantation and valve replacement: genetic assessment of the origin of the cells by means of deoxyribonucleic acid profiles. J Thorac Cardiovasc Surg 1995;109:218-3.

26. Valente M, Faggian G, Billingham ME, et al. The aortic valve after heart transplantation. Ann Thorac Surg 1995;60:S135-40.

27. Jarcho J, Naftel DC, Shroyer TW, et al. Influence of HLA mismatch on rejection after heart transplantation: a multiinstitutional study. The Cardiac Transplant Research Database Group. J Heart Lung Transplant 1994;13:583-96.

28. Sheldon S, Hasleton PS, Yonan NA, et al. Rejection in heart transplantation strongly correlates with HLA-DR antigen mismatch. Transplantation 1994;58:719-22.

29. Opelz G, Wujciak T. The influence of HLA compatibility on graft survival after heart transplantation. The Collaborative Transplant Study [see comments]. N Engl J Med 1994;330:816-9.

30. Walluscheck KP, Steinhoff G, Haverich A. Endothelial cell seeding of native vascular surfaces. Eur J Vasc Endovasc Surg 1996; 11:290-303.

31. Harprecht J, Westphal E, Müller-Ruchholtz W. Production and application of new monoclonal antibodies against human lymphocyte antigen-A and -B antigens. Diagn Clin Immunol 1988;5:388-92. 